- Letter

\title{
A New Role of Case Reports in Family Medicine and Primary Care
}

\author{
Ki Dong Ko* \\ Department of Family Medicine, Gachon University Gil Medical Center, Incheon, Korea
}

\section{To the Editor}

I recognize that the Case Report section of our Korean Journal of Family Medicine (KJFM) is made up of rare and unique cases. New hypotheses could be generated from a single case report—or preferably several single case reports—or a case series. ${ }^{1)}$ Following this, the hypotheses must be tested with formal research methods (i.e., observational and experimental studies) which are designed to confirm them. ${ }^{1)}$ I am aware that the discoveries of the side effect of thalidomide ${ }^{2)}$ and the therapeutic effect of lithium in bipolar patients, ${ }^{3)}$ and the successful treatment of infantile hemangioma with propranolol ${ }^{4)}$ are notable examples of new hypotheses generated from case reports of novel cases. Therefore, reports of novel and challenging cases play an important role in terms of clinical research and epidemiology.

However, I would like to suggest that the Case Report section include relatively common cases with new or important insights, from the perspective of family medicine and primary care. Of course, I'm not referring to typical cases, which are presented in textbooks or lectures. Explained below are two main reasons to suggest the inclusion of additional contents in the Case Report section.

First, the Case Report section is educationally valuable to medical residents, as clinical learning is, to a large degree, case-based. Nevertheless, our residents have insufficient patient care experience. ${ }^{5)}$ Taking into consideration the aims and scope of our journal, the Case Report section is especially suitable for demonstrating the diversity of clinical manifestations, clinicians' diagnostic reasoning, disease management, and follow-up. Many journals already include regular sections dedicated to educational case-based studies, such as Case Report of the Massachusetts General Hospital in the New Eng- land Journal of Medicine and Case Reports/Images in Clinical Medicine in the Journal of General and Family Medicine.

Second, the Case Report section is an effective tool with which family physicians or primary care providers may share a range of ideas and experiences regarding complicated courses of illness, associations of diseases, and side effects of drugs, amongst others. Family physicians or primary care providers spend the majority of their time treating common problems, and, indeed, often confront questions and concerns. As a consequence, they have excellent opportunities to improve their practices when Case Report sections include common diseases presenting in uncommon ways, cases which expand understanding of disease pathogenesis and allow us to rethink established medical beliefs, as well as cases in which errors were made.

In light of the above, it is my hope that KJFM will take on a new and expanded role in helping improve the education of medical residents and our day-to-day clinical practices through the inclusion of the Case Report section.

\section{CONFLICT OF INTEREST}

No potential conflict of interest relevant to this article was reported.

\section{ORCID}

Ki Dong Ko: https://orcid.org/0000-0003-2181-994X

\section{REFERENCES}

1. Nissen T, Wynn R. The clinical case report: a review of its merits and limitations. BMC Res Notes 2014;7:264. 
2. Rehman W, Arfons LM, Lazarus HM. The rise, fall and subsequent triumph of thalidomide: lessons learned in drug development. Ther Adv Hematol 2011;2:291-308.

3. Johnson FN. The history of lithium therapy. London: Macmillan; 1984.

4. Leaute-Labreze C, Harper JI, Hoeger PH. Infantile haemangioma.
Lancet 2017;390:85-94.

5. Kim YJ, Park EW, Cheong YS, Choi EY, Baek KH, Sung HY, et al. Residents' expectation of family medicine-specific training program and its current state. Korean J Fam Med 2011;32:390-8. 